OPEN ACCESS

Edited by:

Aamir Ahmad,

University of Alabama at Birmingham,

United States

Reviewed by:

Alex C. Kornke,

University of York, United Kingdom

Mohd Farhan,

King Faisal University,

Saudi Arabia

*Correspondence:

Shui-long Guo

slong.guo@163.com

Peng Li

lipeng@ccmu.edu.cn

${ }^{+}$These authors have contributed equally to this work

Specialty section:

This article was submitted to Molecular and Cellular Oncology,

a section of the journal

Frontiers in Oncology

Received: 14 December 2020

Accepted: 08 March 2021

Published: 01 September 2021

Citation:

Cao R-z, Min L, Liu S, Tian R-y, Jiang H-y, Liu J, Shao L-I, Cheng R, Zhu S-t, Guo S-l and LiP (2021) Rictor

Activates Cav 1 Through the Akt Signaling Pathway to Inhibit the Apoptosis of Gastric Cancer Cells.

Front. Oncol. 11:641453.

doi: 10.3389/fonc.2021.641453

\section{Rictor Activates Cav 1 Through the Akt Signaling Pathway to Inhibit the Apoptosis of Gastric Cancer Cells}

\author{
Rui-zhen Cao ${ }^{1,2+}$, Li Min ${ }^{1 \dagger}$, Si Liu ${ }^{1}$, Ru-yue Tian ${ }^{1}$, Hai-yan Jiang ${ }^{1,3}$, Juan Liu ${ }^{1,4}$, \\ Lin-lin Shao ${ }^{1}$, Rui Cheng ${ }^{1}$, Sheng-tao Zhu ${ }^{1}$, Shui-long Guo ${ }^{1 *}$ and Peng Li $^{1 *}$ \\ 1 Department of Gastroenterology, Beijing Friendship Hospital, Capital Medical University, National Clinical Research Center \\ for Digestive Disease, Beijing Digestive Disease Center, Beijing Key Laboratory for Precancerous Lesion of Digestive Disease, \\ Beijing, China, ${ }^{2}$ Department of Gastroenterology, Ordos Central Hospital, National Clinical Research Center for Digestive \\ Disease-Ordos Subcenter, Ordos, China, ${ }^{3}$ Department of Gastroenterology, Beijing University of Chinese Medicine Third \\ Affiliated Hospital, Beijing, China, ${ }^{4}$ Department of Gastroenterology, Shanxi Province Cancer Hospital, Shanxi Medical \\ University, Taiyuan, China
}

Background: Rapamycin-insensitive companion of mammalian target of rapamycin (Rictor) protein is a core subunit of mammalian target of rapamycin complex 2, and is associated with cancer progression. However, the biological function of Rictor in cancer, particularly its clinical relevance in gastric cancer (GC) remains largely unknown.

Methods: Rictor expression and its association with clinicopathologic characteristics in GC were analyzed by immunohistochemistry. Effect of Rictor and Caveolin-1 (Cav 1) on GC cells apoptosis was evaluated via overexpression experiment in vitro. Mechanisms of Rictor and Cav 1 in GC were explored through overexpression and knockdown, by immunofluorescence and western blot analyses.

Results: Rictor was upregulated in GC, and mainly located in the cytoplasm of cancer cells. Moreover, higher Rictor levels were associated with worse prognosis. Rictor could inhibit GC cell apoptosis and promote cell growth in vitro. The results of immunofluorescence revealed that Cav 1 localized in GC cell membrane but did not co-localize with Rictor. Further, Rictor regulated apoptosis-related proteins, long noncoding RNAs and also activated cellular signaling, thereby positively regulating Cav 1 expression. This effect was attenuated by the Akt inhibitor ly294002. Cav 1 did not significantly affect the ability of Rictor to inhibit tumor cell apoptosis.

Conclusions: Rictor is upregulated in GC and associated with worse prognosis. It inhibits tumor apoptosis and activates Cav 1 through the Akt signaling pathway to inhibit the apoptosis of GC cells. Rictor is, therefore, a promising prognostic biomarker and possible therapeutic target in GC patients.

Keywords: Rictor, Cav 1, Akt, Apoptosis, Gastric cancer 


\section{INTRODUCTION}

Gastric cancer (GC) is one of the most common malignancies worldwide, ranking fifth in incidence and third in mortality (1). East Asia is particularly affected by GC, as indicated by the comparative high mortality (2). GC is the second most common cause of death in China, despite a steady decline in western countries. Owing to high rates of metastasis and recurrence, the five-year overall survival rate for advanced GC is $20 \%$ (3). In recent years, with the continued advancements in molecular biology, signaling pathways and targeted therapy have gradually become the focus of GC research, and are expected to provide more effective means for the treatment of GC (4). The most recent advancements in GC research are in the area of noncoding nucleic acids such as long-non-coding RNAs and miRNAs (5-9).

The mammalian target of rapamycin (mTOR) signaling pathway is a key pathway that affects progression of GC. It is often highly activated in GC, and is closely related to clinicopathological characteristics, such as recurrence and metastasis. mTOR exists in the form of mammalian target of rapamycin complex 1 (mTORC1) and mammalian target of rapamycin complex 2 (mTORC2). As one of the core subunits of complex mTORC2, Rictor is the skeleton protein of mTORC2. It is critical for stability and necessary for normal functioning of mTORC2. Rictor is mainly responsible for sensing growth factor concentration, regulating cell proliferation, survival, metabolism and cytoskeletal remodeling. It has been demonstrated through immunohistochemical studies that Rictor expression is increased in association with tumor progression, and that it correlates with poor prognosis of GC patients (10). Current studies have confirmed that Rictor promotes cell growth and proliferation by activating protein kinase $\mathrm{B}(\mathrm{Akt})$, promoting cell resistance to apoptosis and promoting angiogenesis $(11,12)$. Rapamycin has not been as successful as expected in clinical trials. The main reason for this may be the different sensitivities of the two mTOR complexes. mTORC1 is sensitive to treatment with rapamycin. Treatment with rapamycin or its analogues primarily inhibits the mTORC1/S6K pathway and alleviates the negative feedback loop receptor (IGF-1R) from S6K to insulin-like growth factor-1, signaling mTORC2 through the complete pathway leading to Akt activation paradoxically (13). The activation of Akt is concerning because it promotes cell survival and drug resistance, and therefore treatment with an MTORC1 inhibitor might not be beneficial. Inhibition of mTORC2 may eliminate the adverse signaling effects of mTOR inhibitors. Therefore, it is important to further study and characterize the potential therapeutic targets of mTORC2 and explore the associated molecular mechanism in tumors, particularly in GC (14-16).

Caveolin-1 (Cav 1), a membrane protein with a relative molecular weight of 2.1-2.4 $\times 10^{4}$, is the main component of caveolae, which is involved in malignant transformation, malignant proliferation, invasion, metastasis and many other biological behaviors of cells. Cav 1 enhances RANKL-induced GC cell migration (17) and also plays a role in epithelial to mesenchymal transition (EMT) impacting the clinicopathological features of GC $(18,19)$. IGF-I receptor (IGF-IR) localizes in caveolae and tyrosine phosphorylates Cav 1. Cav 1 is involved in the internalization of IGF-IR and directly interacts with IGF-IR and its substrate (20). Cav 1 contributes to anchorageindependent growth and anoikis resistance of human GC SGC7901 cells via activation of Src-dependent EGFR-ITGB1 signaling (21). The mechanosensitive caveolin-1 activation-induced PI3K/ Akt/mTOR signaling pathway promotes cancer motility, invadopodia formation and metastasis in vivo (22). This is agreement with the general information on Akt signaling in human cancers, including GC (23-26). Given this information, we hypothesized there may be an interaction in GC between Rictor and Cav 1 that affects the biological behavior of tumor cells.

In this study, we report overexpression of Rictor in GC and its association with worse prognosis. Particularly, we revealed an anti-apoptosis effect of Rictor in GC cells and that Rictor activates Cav 1 through the Akt signaling pathway to inhibit the apoptosis of GC cells.

\section{MATERIALS AND METHODS}

\section{Patients and Clinical Data}

In total, 92 patients with gastric carcinoma who underwent surgical resection were recruited for this study. Among them, 84 cases without distant metastasis received gastrectomy together with a standard D2 lymph node dissection. The study was approved by the Ethic Committee of Capital Medical University (\#66128) The other eight metastatic patients with primary tumor complications, such as obstruction or bleeding, underwent palliative stomach resection. Pathological tumor staging was based on the 7th edition of the Union for International Cancer Control (UICC) TNM staging system. All participants had complete follow-up. The overall survival (OS) time was determined from the date of surgery to the follow-up deadline or date of death. The follow-up deadline was July 2015, and the median follow-up period was 8-9 years (OutDo Biotech Co., Ltd. Shanghai, China).

\section{Reagents and Antibodies}

Primary antibodies used were rabbit monoclonal anti-Rictor (ab70374, Abcam, Cambridge, MA), anti-Cav 1(Rabbit mAb \#3276), Akt (pan) (Rabbit mAb \#4691, Phospho-Akt (Ser473) (Rabbit mAb \#4060) (Cell Signaling Technology, Shanghai, China), Caspase-3 monoclonal antibody (CPP32-4-1-18), Bcl-2 polyclonal antibody (PA5-11379), Bax monoclonal antibody (6A7), actin monoclonal antibody (ACTN05 (C4) and Biotin (ThermoFisher, Shanghai, China). Rictor plasmid (Addgene $\# 1860$ ) and Cav 1 plasmid (Addgene27703) were purchased from Addgene (USA). Rictor-siRNA and Cav 1-siRNA were purchased from GenePharma Co., Ltd. (Shanghai, China). Ly294002 (\#9901) was purchased from Cell Signaling Technology. Human GC cell lines SGC-7901 and AGS were purchased from iCell Bioscience Inc (Shanghai, China) in Feb 2018. 


\section{Immunohistochemistry}

Tissue microarrays were constructed by Shanghai Xinchao Biotechnology Co., Ltd. (Shanghai, China). Prepared slides were incubated at $65^{\circ} \mathrm{C}$ for $1 \mathrm{~h}$, After incubation, the sections were deparaffinized in xylene and rehydrated in alcohol. Following antigen retrieval with high pressure, endogenous peroxidase activity was blocked with $3 \% \mathrm{H}_{2} \mathrm{O}_{2}$ for $20 \mathrm{~min}$. Sections were blocked with goat serum for $1 \mathrm{~h}$ and incubated with primary antibody against Rictor (Abcam, dilution of 1:100) overnight at $4^{\circ} \mathrm{C}$. The next day, the tissues were incubated with Universal second antibodies (goat anti-rabbit and mouse) for $60 \mathrm{~min}$ at room temperature. Immunostaining was carried out with DAB substrate kit (Thermo Scientific, Waltham, USA), followed by immersion into hematoxylin for nuclear counterstaining.

\section{Scoring of Staining}

The results of immunohistochemical staining were evaluated by two independent investigators according to a semiquantitative grading system based on both proportion of stained cells and their intensity. The extent of staining was scored as no staining $=0$; $<1 / 3$ staining $=1 ; 1 / 3$ to $2 / 3$ staining $=2$; and $>2 / 3$ staining $=3$. Staining intensity was scored as: none $=0$; weak $=1$; medium $=2$; and strong $=3$. The intensity and percentage scores were added to give a final score ranging from 0 to 6 . The results of immunostaining were divided into two groups where 0-2 was considered negative (-) and 3-6 was considered positive (+).

\section{Cell Culture and Plasmid Transfections}

The two cell lines, SGC-7901 and AGS were respectively cultured in Dulbecco's Modified Eagles Medium (DMEM) with 10\% Fetal Bovine Serum(FBS) and Ham's F-12K(Kaighn's) medium $(\mathrm{F}-12 \mathrm{~K})$ with $20 \% \mathrm{FBS}$ in a humidified incubator at $37^{\circ} \mathrm{C}$ with $5 \% \mathrm{CO}_{2}$. Cell lines used in the experiments were authenticated using short tandem repeat (STR) profiling in the Genomics core facility of Capital Medical University on an annual basis, with last authentication in April, 2020, and passaged less than 5 times at any given time. When SGC-7901 and AGS cells grew to 50$60 \%$ confluency, the Rictor and Cav 1 plasmids and vectors were used to infect cells using lipofectamine 3000 and P3000 (Life Technologies, China), according to the manufacturer's instructions. Rictor-siRNA and Cav 1-siRNA were transfected into two the cell lines by using lipofectamine 3000 according to the provided protocols. The transfection efficacy was determined by western blot.

\section{Cell Apoptosis Assay}

Cell apoptosis was measured by Annexin V-FITC/PI Apoptosis Detection Kit (KeyGEN, Guangzhou, China). Cells were collected, were digested and isolated in Dulbecco's PhosphateBuffered Saline (DPBS), washed with cold phosphate-buffered saline (PBS) 3 times, PBS solution and re-suspended in binding buffer. Cells were stained by AnnexinV-FITC and 7-
aminoactinomycinD (7-AAD) (BD Biosciences, New York, USA) for $15 \mathrm{~min}$, sorted using the FACS Calibur system (BD Biosciences) and counted apoptotic cells when AnnexinV staining was positive.

\section{Cell Survival Assay (MTS)}

To examine the effects of Rictor on the proliferation of GC cells, onestep 3-(4,5-dimethylthiazol-2-yl)-5-(3-carboxymethoxyphenyl)-2(4-sulfophenyl)-2H-tetrazolium (MTS) assays were conducted. In total, 2000 cells/well in $100 \mu \mathrm{L}$ of medium were seeded in a 96-well plate after transfection, and detected at 8h, 32h, and 56h using an enzyme-labelled meter (Spectramax M3, Molecular Devices, Shanghai, China) $2 \mathrm{~h}$ after the addition of MTS.

\section{EdU Cell Proliferation Assay}

After Rictor plasmid transfection, the cells were cultivated for $48 \mathrm{~h}$.Then 20,000 cells/well were seeded in a 24 -well plate. In total, $100 \mu \mathrm{L}$ incubation EdU medium(1000:1) was added to each well and incubated for $2 \mathrm{~h}$. After washing with PBS, the cells were fixed for $30 \mathrm{~min}$ in $4 \%$ paraformaldehyde. Then, $2 \mathrm{mg} / \mathrm{mL}$ glycine was added to the wells and further incubated for $5 \mathrm{~min}$. Then, the wells were washed with PBS before adding penetrating agent (PBS containing $0.5 \%$ Triton $\mathrm{X}-100$ ) followed by incubation for $10 \mathrm{~min}$, at room temperature in the dark. Further, cells were incubated with Apolle dye for $30 \mathrm{~min}$, penetrant decolorizing cleaned cells for $10 \mathrm{~min}$ thrice, Then, for DNA staining, cells were incubated with the reaction solution for 30min in the dark at room temperature. After washing with PBS thrice, the product was tested on Olympus IX51.

\section{Immunofluorescence}

To determine the cellular localization of Rictor and Cav 1, SGC7901 and AGS cell lines were seeded on sterile coverslips in the well of 6-well plates, washed with PBS three times, then cells were fixed with $4 \%$ paraformaldehyde for $15 \mathrm{~min}$, permeabilized with $0.25 \%$ Triton X-100 in PBS for 10 min, followed by blocking in $5 \%$ BSA in PBST for $1 \mathrm{~h}$. Cells were then incubated overnight in $4^{\circ} \mathrm{C}$ with special primary antibody: anti-Rictor (dilution 1:100) and anti-Cav 1(dilution 1:100). The next day, primary antibody was removed, cells were washed with PBS, and incubated in a mixture of two fluorescent secondary antibodies (Alexa Fluor 488-conjugated anti-mouse IgG and Alexa Fluor 594conjugated anti-rabbit IgG) (dilution1:100,Life Technologies) in the dark for $2 \mathrm{~h}$, Cells were stained with DAPI and photographed by confocal microscopy (IX83, FLUOVIEW FV1200, Olympus).

\section{Western Blot}

Treated cells were collected and lysed using lysate buffer on ice for $30 \mathrm{~min}$, and protein concentration was determined by BCA assay. Equal amounts of proteins $(30 \mu \mathrm{g})$ were separated by SDSPAGE and transferred to nitrocellulose membranes. After 
blocking in 5\% non-fat milk for $2 \mathrm{~h}$, the membranes were incubated with primary antibodies against Rictor, p-Akt (Ser473), Akt, Cav 1, Caspase-3, Bcl-2, Bax or $\beta$-actin overnight at $4^{\circ} \mathrm{C}$. The following day, membranes were incubated with anti-rabbit or anti-mouse secondary antibodies at room temperature for $1 \mathrm{~h}$. Finally, immunoblots were visualized using enhanced chemiluminescence (ECL) reagent (Thermo Scientific, USA). $\beta$-actin was used as a loading control.

\section{Statistical Analysis}

Data are presented as Means \pm SD. All statistical analyses were plotted with the GraphPad Prism (Version 8.0.1) and IBM SPSS Statistical 25. Statistical tests are one-sided or two-sided, t tests were conducted to evaluate the differences between two groups, while ANOVA tests were used in multiple comparable groups. Log-rank tests and Kaplan-Meier plots were applied to assess and show differences in overall survival (OS) between subgroups. Cox proportional hazard models were used for multiple-variants analysis. $\mathrm{P}<0.05$ was considered to indicate a statistically significant difference.

\section{RESULTS}

\section{Characterization of Rictor Expression}

To evaluate the expression of Rictor in GC, immunohistochemical assays were performed on 92 patients with GC and adjacent normal tissues. We found that Rictor localized in the cytoplasm of cancer cells, but not in the surrounding stroma cells. We also found that expression of Rictor was significantly increased in GC tissues compared with normal tissues (Figure 1A). Kaplan-Meier survival analysis with log-rank test for OS in all 92 patients with gastric cancer (Figure 1B) and survival analysis of 92 cases in gastric cancer (Figure 1C). Clinicopathological statistical analyses indicated that Rictor expression was correlated with tumor size, depth of invasion, lymph node metastasis, TNM stage, WHO grading and tumor thrombus. There was no significant association with gender, age, tumor location or distant metastasis (Table 1). Taken together, our data indicates that Rictor was located in GC cells but not in the surrounding stroma cells in GC tissues, and could be used as a potential prognostic biomarker for GC patients.

\section{Rictor Promoted Growth of GC Cells In Vitro}

To investigate the growth-promoting function of Rictor on GC cells, we tested apoptosis rates of SGC-7901 and AGS cells after Rictor overexpression by flow cytometry. The results showed that overexpression of Rictor level significantly inhibited apoptosis in GC cells (Figures 2A, B). Rictor down-regulated Caspase- 3 and $\mathrm{Bax}$, and up-regulated $\mathrm{Bcl}-2$ to achieve apoptosisinhibiting effect on GC cells (Figures 2C, D). To further explore the biologic functions of Rictor in GC, we overexpressed Rictor in SGC-7901 and AGS cells to test cell viability by EdU (Figures 2E, F) and MTS assays (Figures 2G, H). The results suggested that overexpression of Rictor markedly promoted cell viability in SGC-7901 and AGS. We further, evaluated effect of Rictor on long-non-coding RNAs and found that Rictor induced MALAT1 as well as GMAN (Figures 3A, B), both of which promote GC tumorigenesis $(27,28)$. On the contrary, Rictor down-regulated MEG3 and GAS5 (Figures 3C, D), both of which are tumor suppressive lncRNAs (29).
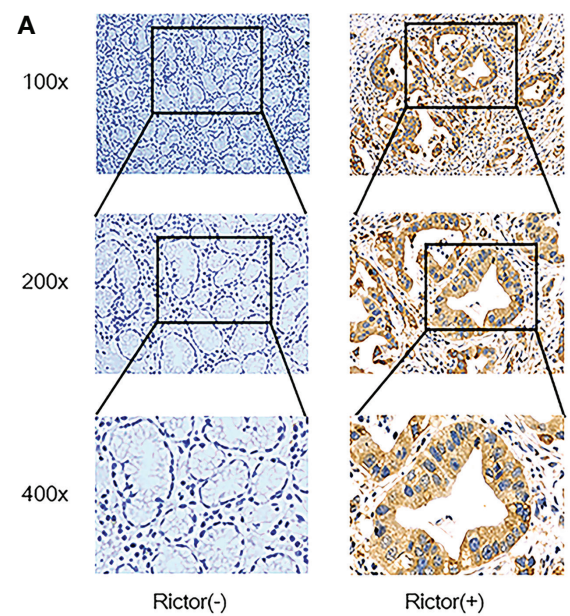
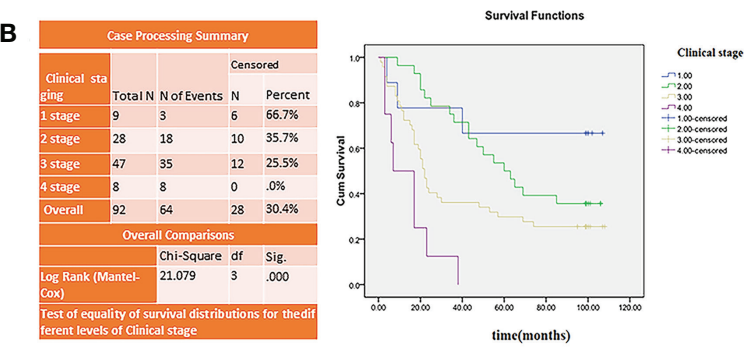

C

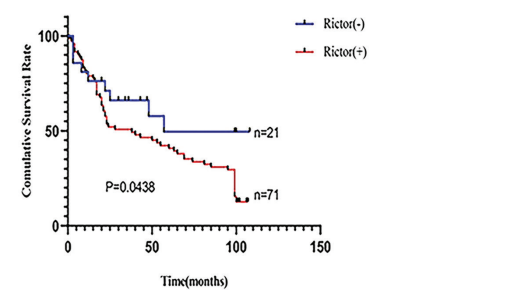

FIGURE 1 | Rictor is upregulated inside GC cells and correlated with poor prognosis in different GC cohorts. (A) Representative immunohistochemical stains for Rictor. (B) Kaplan-Meier survival analysis with log-rank test for OS in all 92 patients with gastric cancer sorted by immunostaining of Rictor. (C) Survival analysis of 92 gastric cancer cases. 
TABLE 1 | Correlation of Rictor expression with clinicopathological characteristics in 92 gastric cancer patients.

\begin{tabular}{|c|c|c|c|}
\hline \multirow[t]{2}{*}{ Factors } & \multirow[t]{2}{*}{ Cases } & \multicolumn{2}{|c|}{ Rictor } \\
\hline & & n (\%) & $P$ value \\
\hline \multicolumn{4}{|l|}{ Gender } \\
\hline Male & 57 & $44(81.5)$ & \multirow[t]{2}{*}{0.238} \\
\hline Female & 35 & $27(77.1)$ & \\
\hline \multicolumn{4}{|l|}{ Age(yr) } \\
\hline$\leq 60$ & 30 & 22(68.8) & \multirow[t]{2}{*}{0.470} \\
\hline$>60$ & 62 & 49(79.0) & \\
\hline \multicolumn{4}{|l|}{ Location } \\
\hline Upper & 11 & 10(90.9) & \multirow[t]{4}{*}{0.173} \\
\hline Central & 24 & $18(75.0)$ & \\
\hline Lower & 49 & 36(73.5) & \\
\hline Diffuse & 8 & $7(87.5)$ & \\
\hline \multicolumn{4}{|l|}{ Size } \\
\hline$<5 \mathrm{~cm}$ & 41 & $35(85.4)$ & \multirow[t]{2}{*}{$0.019^{*}$} \\
\hline$\geq 5 \mathrm{~cm}$ & 51 & 35(68.3) & \\
\hline \multicolumn{4}{|c|}{ Depth of invasion } \\
\hline $\mathrm{Tl}+\mathrm{T} 2$ & 14 & 13(92.9) & \multirow[t]{2}{*}{$0.026^{*}$} \\
\hline $\mathrm{T} 3+\mathrm{T} 4$ & 78 & $58(74.4)$ & \\
\hline \multicolumn{4}{|c|}{ Lymph node metastasis } \\
\hline Negative & 23 & $18(78.2)$ & \multirow[t]{2}{*}{$0.037^{*}$} \\
\hline Positive & 69 & $53(76.8)$ & \\
\hline \multicolumn{4}{|c|}{ Distant metastasis } \\
\hline $\mathrm{MO}$ & 84 & $64(76.2)$ & \multirow[t]{2}{*}{$0.033^{*}$} \\
\hline M1 & 8 & $7(87.5)$ & \\
\hline \multicolumn{4}{|c|}{ TNM stage } \\
\hline I & 9 & $9(100)$ & \multirow[t]{4}{*}{$0.009^{*}$} \\
\hline$\|$ & 28 & $20(71.4)$ & \\
\hline III & 47 & $35(74.5)$ & \\
\hline IV & 8 & $7(87.5)$ & \\
\hline \multicolumn{4}{|c|}{ Who grading } \\
\hline Grade 1 & 14 & $14(100)$ & \multirow[t]{3}{*}{$0.029^{*}$} \\
\hline Grade 2 & 68 & $50(73.5)$ & \\
\hline Grade 3 & 10 & $7(70.0)$ & \\
\hline \multicolumn{4}{|c|}{ Tumor thrombus } \\
\hline Negative & 79 & $60(75.9)$ & \multirow[t]{2}{*}{$0.046^{*}$} \\
\hline Positive & 13 & 11(84.6) & \\
\hline
\end{tabular}

Statistical analysis indicated that Rictor expression was correlated with tumor size, depth of invasion, lymph node metastasis, TNM stage, WHO grading and tumor thrombus. There was no significant association with gender, age, tumor location and distant metastasis. ${ }^{*} P<0.05$.

\section{Cav 1 Inhibited Apoptosis of Gastric Cancer Cells}

To investigate the function of Cav 1 on GC cells, we tested apoptosis rates of SGC-7901 and AGS cells overexpressing Cav 1, by flow cytometry. The results showed that overexpression of Cav 1 level significantly inhibited apoptosis in GC cells (Figures 4A, B). After Rictor overexpression in SGC-7901 and AGS cells, western blot analyses showed an increase of Cav 1 expression (Figures 4C, D). In GC cells, Rictor and Cav 1 did not co-localize (Figures 4E, F), suggesting there was no direct interaction between them. Western blot analysis indicated that p-Akt and Cav 1 levels increased after transfection of both SGC-7901 and AGS cells with the Rictor plasmid (Figures 4G, H).

\section{Rictor Activates Cav 1 Through the Akt Signaling Pathway to Inhibit Apoptosis of Gastric Cancer Cells}

Two different cell lines (SGC-7901 and AGS) were transfected with Rictor-siRNA to verify Rictor-siRNA knock down efficiency (Figures 5A, B). After transfection with RictorsiRNA, the protein levels of p-Akt and Cav 1 were analyzed (Figures 5C, D). After transfection of Rictor plasmid into SGC-7901 and AGS cells for $24 \mathrm{~h}, 20 \mu \mathrm{M}$ of the Akt inhibitor ly294002 was added. Western blot analysis showed the levels of p-Akt and Cav 1 decreased (Figures 5E, F). Apoptosis increased in both cell lines, after transfection with the Rictor plasmid for $24 \mathrm{~h}$ and a $24 \mathrm{~h}$ treatment with Akt inhibitor ly294002 (Figures 5G, H).

\section{Knockdown Cav 1 Had No Effect on Apoptosis Inhibition by Rictor Overexpression}

To investigate whether Cav 1 had a direct effect on apoptosis inhibition due to Rictor overexpression, we co-transfected the Rictor plasmid and three Cav 1-siRNAs into SGC-7901 and AGS cells, then tested apoptosis rates by flow cytometry. The results indicated that knocking down Cav 1 had no effect on apoptosis inhibition by Rictor overexpression (Figures 6A, B).

Finally, the prospective Rictor signaling pathway is summarized in Figure 6C. Rictor inhibited the apoptosis of tumor cells by regulating apoptosis-related proteins, and activated the tumor cell apotosis inhibition effect of Cav 1 through the Akt signaling pathway. Cav 1 did not directly affect the inhibitory effect of Rictor on apoptosis.

\section{DISCUSSION}

Oncogenic signaling and metabolic alterations are interrelated in cancer cells. mTOR, which is frequently activated in cancer, controls cell growth and metabolism (30). This signaling pathway is often highly activated in GC, and is closely related to clinicopathological characteristics, such as recurrence and metastasis (31). Studies have proved, through immunohistochemistry, that the increase in Rictor expression is associated with tumor progression and poor prognosis in GC patients (10). It has also been reported that p-mTOR could be used as a prognostic marker, suggesting that investigations of mTOR inhibitors may provide a novel therapeutic approach. mTOR exerts additional functions when combined with Rictor to form mTORC2 (32). However, the expression and role of Rictor remains unclear in GC. In this study, we found that Rictor was expressed at $77.17 \%$ in GC versus $25.33 \%$ in adjacent mucosa, and this overexpression significantly correlated with tumor size, depth of invasion, lymph node metastasis, and TNM stage. This indicates that Rictor is involved in tumor growth and metastasis. In addition, KaplanMeier analysis showed that Rictor positive expression predicted poorer overall survival. In renal cancer, Rictor is closely related 
A

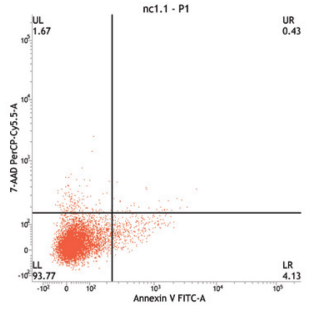

B

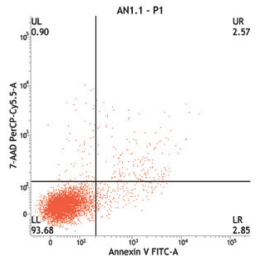

E
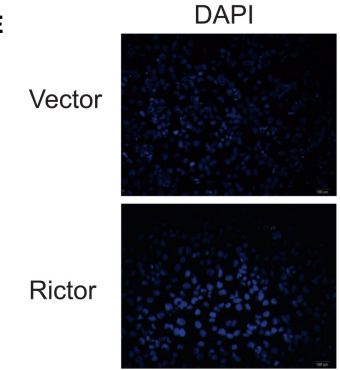

F

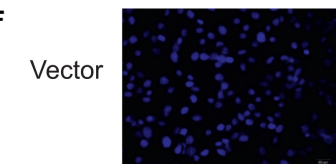

Rictor

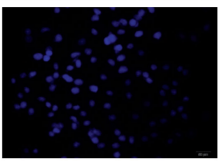

G

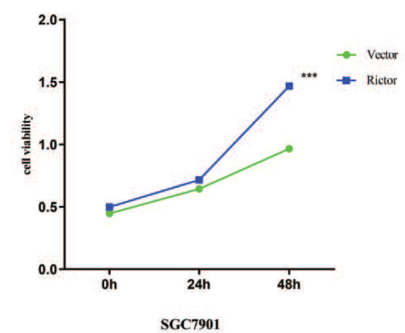

SGC-7901 $\underset{0.20}{\text { UR }}$
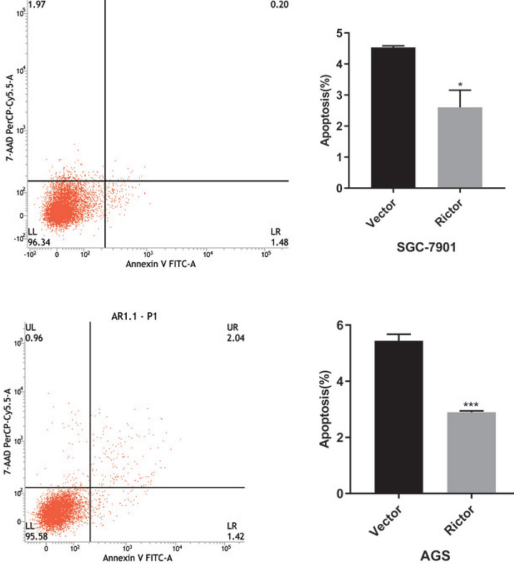

UR.

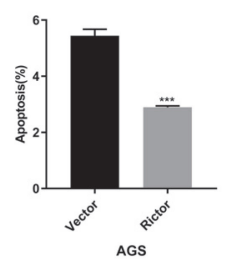

C

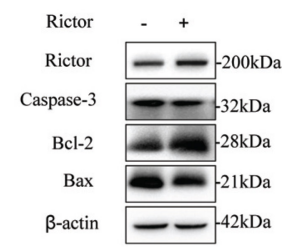

SGC-7901

D

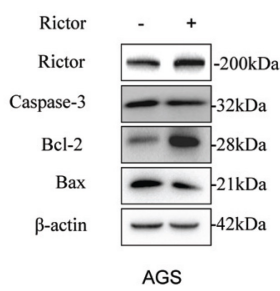

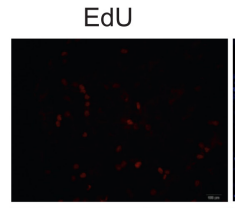

Merge
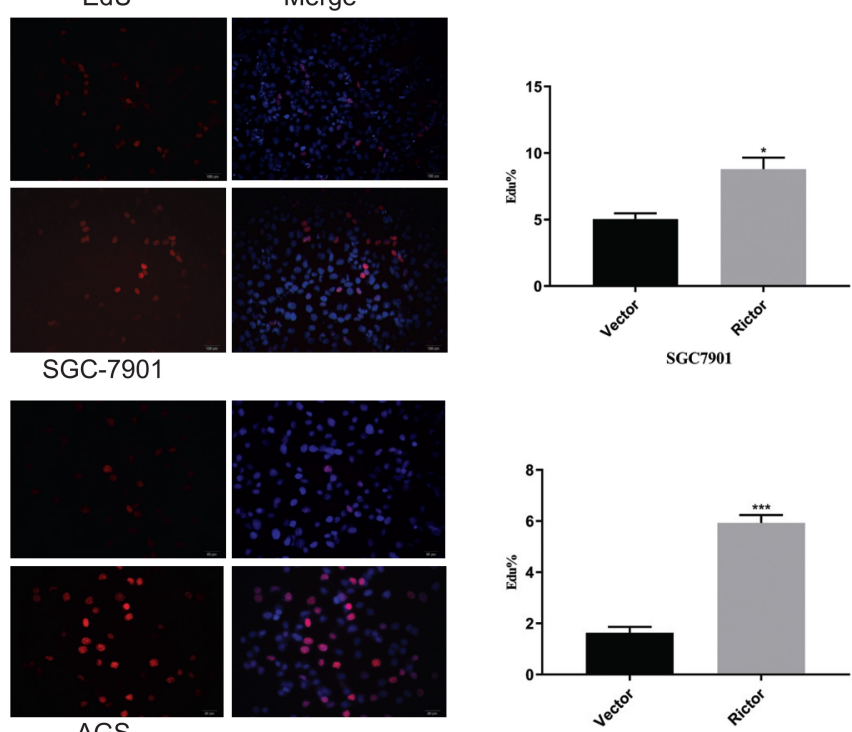

AGS

H

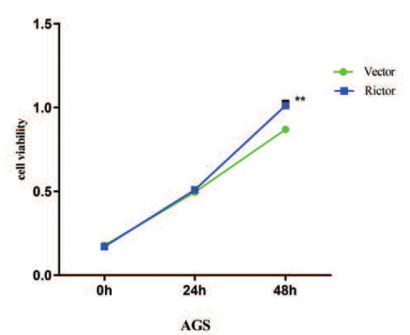

FIGURE 2 | Growth promoting effect of Rictor in gastric cancer cell lines. (A) Transfection of Rictor plasmid can inhibit the apoptosis of SGC-7901 cells (n=9). (B) Transfection of Rictor plasmid can inhibit the apoptosis of AGS cells ( $n=9)$. (C) Expression of apoptosis related proteins after transfection with Rictor plasmid in SGC-7901 cells. (D) Expression of apoptosis related proteins after transfection with Rictor plasmid in AGS cells. $\beta$-actin served as loading control. (E) EdU verification that transfection of the Rictor plasmid increased proliferation of SGC-7901 cells ( $n=3$ ). (F) EdU verification that transfection of the Rictor plasmid increased proliferation of AGS cells ( $n=3$ ). (G) Transfection of Rictor plasmid can increase the proliferation of SGC-7901 cells $(n=3)$. (H) Transfection of Rictor plasmid can increase the proliferation of AGS cells ( $n=3$ ). Values represent the Means $\pm \mathrm{SD}$. ${ }^{\star} \mathrm{P}<0.05$, ${ }^{\star \star} \mathrm{P}<0.01$ and ${ }^{\star \star \star} \mathrm{P}<0.001$ as calculated using the Student's t-test.

to metastasis and cell proliferation of renal cancer cells, and the downregulation of Rictor could inhibit metastasis and proliferation, thus inhibiting tumor growth (33). In mouse mammary glands, downregulation of Rictor can block the expansion and obstruction of ductal branches regulated by mTORC2, as well as the invasion and survival of mammary 
A
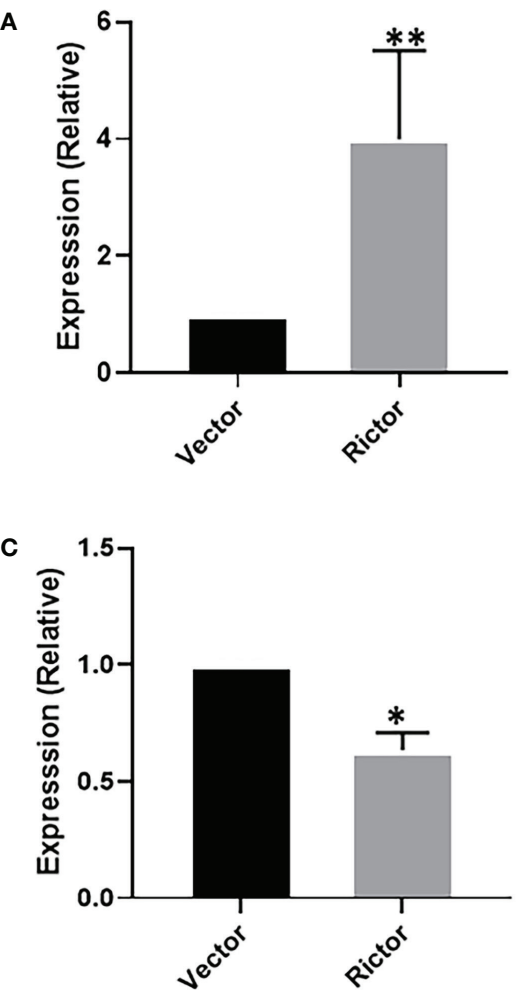

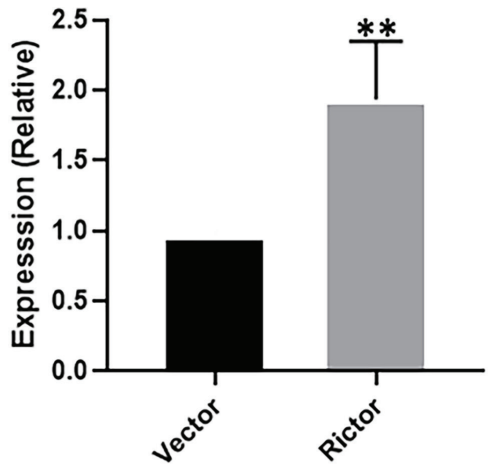

D

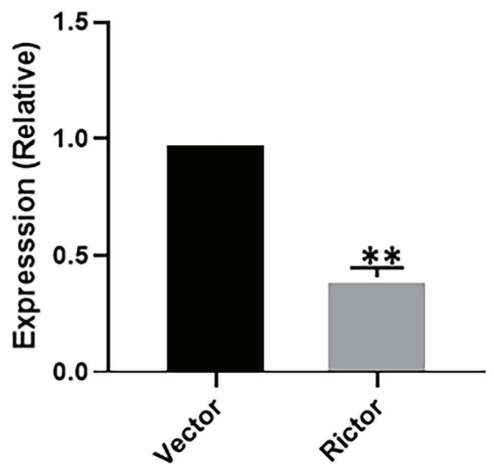

FIGURE 3 | Long-non coding RNAs modulating effect of Rictor in gastric cancer cell line SGC-7901. Transfection of Rictor plasmid increased the expression of IncRNAs (A) MALAT-1 and (B) GMAN and decreased the expression of IncRNAs (C) MEG3 and (D) GAS5. Values in control (vector-transfected cells were assigned a value of ' 1 ' and those in Rictor-transfected cells are presented as comparative fold-change. ${ }^{*} \mathrm{P}<0.05$ and ${ }^{* *} \mathrm{P}<0.01$, as calculated using the Student's t-test.

epithelial cells (34). Rictor is highly expressed in human glioblastomas, and activation of mTORC2 also enhances phosphorylation of the downstream substrate Akt (35). Our results are consistent with the majority of the reported findings. We propose that Rictor positive expression is implicated in progression and metastasis of GC, and might serve as a novel biomarker and therapeutic target. The present study of Rictor expression by immunohistochemistry in human cancer tissues suggests that targeting Rictor/mTORC2 may attenuate tumor growth. As a result, we found that Rictor overexpression can affect the expression of apoptosis-related proteins such as Caspase-3, Bax, and Bcl-2, thereby reducing the apoptosis of GC cells. Targeted inhibition of Rictor leads to growth inhibition and induces apoptosis in both rapamycin-sensitive and rapamycin-resistant CRCs, suggesting that selective targeting of mTORC2 may represent a novel therapeutic strategy for treatment of CRC (36). The effects of Rictor on cell proliferation and apoptosis have been observed in malignant pheochromocytoma (37), melanoma $(38,39)$ and lung cancer (40).

Resistance of solid tumors to chemo-and radiotherapy remains a major obstacle in anti-cancer treatment (41). Cav 1 has gained attention owing to its high expression in many tumors, and high Cav 1 levels are correlated with a worse clinical outcome. Cav 1 plays an important role in modulating tumor host interactions by promoting tumor growth, metastasis, therapy resistance, and cell survival. Understanding these interactions and thus, inhibiting Cav 1, may offer a novel strategy for preventing cancer therapy resistance and improving clinical outcomes. Cav 1 is an integral membrane protein that is abundantly expressed in adipocytes, endothelial cell, pneumocytes, fibroblasts, and muscle cells (42-44), and is involved in cell signaling and transport. It is also involved in caveola-mediated endocytosis, and therefore regulates numerous cellular processes by transmitting extracellular signals via intracellular pathways $(45,46)$. Cav 1-dependent signal transduction regulates cell cycle, proliferation and invasion (47) and cell death (48-50). The molecular mechanisms of Cav 1 , mediating radio and chemoresistance of cancer cells, have been increasingly studied in the last few years. High Cav 1 expression, correlated with worse clinical outcomes and drug resistance, has been reported in ovarian, colon, and breast cancer (51-53). High Cav 1 expression is also associated with RAF-ERK signaling, cell cycle progression and colony forming ability (54). Patients with Cav 1-positive tumors, post-gastrectomy, display decreased disease-free and overall survival (55). Moreover, Cav 1 expression is associated with poor prognosis in GC (56). Cav 1 expression is low in GC patients in comparison to healthy 
A

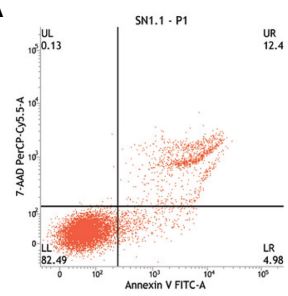

B

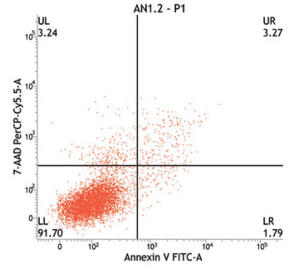

${ }_{12.4}^{\text {UR }}$
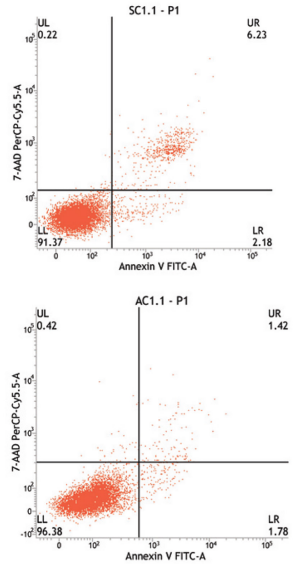

E

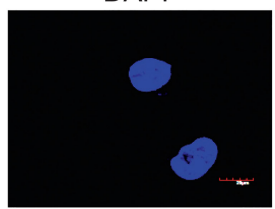

F
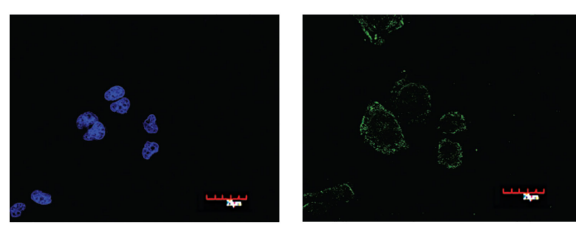

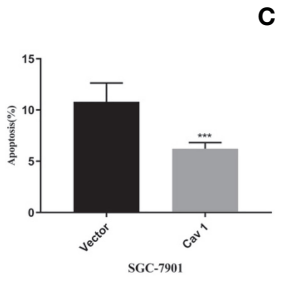

C

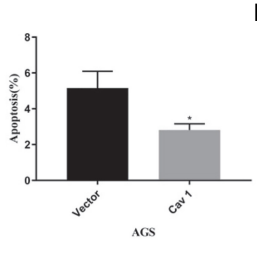

D

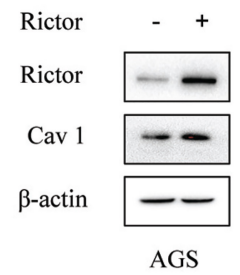

G

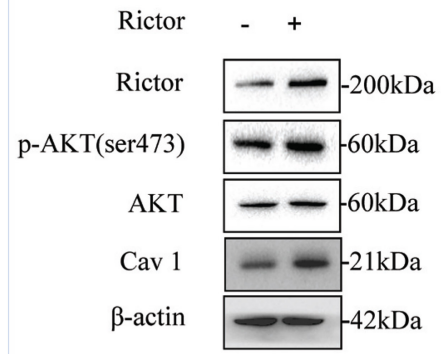

SGC -7901

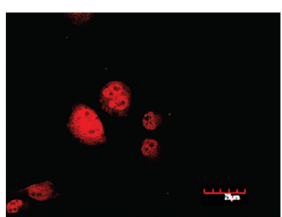

AGS

Cav 1

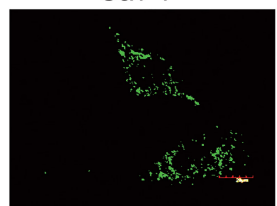

Rictor
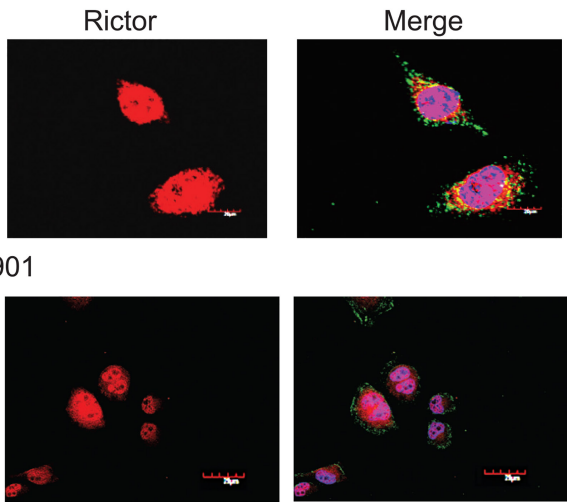

H

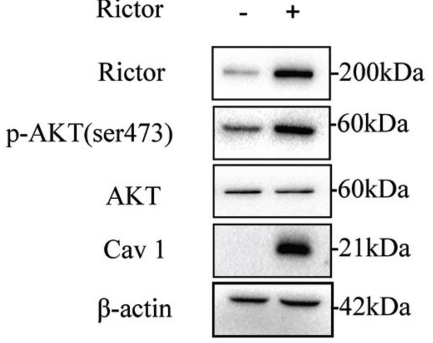

AGS

FIGURE 4 | Cav 1-induced inhibition of apoptosis of gastric cancer cells and association between Rictor and Cav 1. (A) Transfected Cav 1 plasmid could inhibit the apoptosis of SGC-7901 cells ( $n=9$ ). (B) Transfected Cav 1 plasmid could inhibit the apoptosis of AGS cells $(n=9)$. Values represent the Means \pm SD, *P $<0.05$ and ${ }^{* \star *} \mathrm{P}<0.001$ were calculated using Student's t-test. (C) Western blot analysis of the increase of Cav 1 expression with Rictor overexpression in SGC-7901 cells. (D) Western blot analysis of the increase of Cav 1 expression with Rictor overexpression in AGS cells. (E, F) Immunofluorescence showed no co-localization between Rictor and Cav 1. (G) Western blot analysis of p-Akt and Cav 1 levels increased after transfection of SGC-7901 cells with Rictor plasmid. (H) Western blot analysis of $p$-Akt and Cav 1 levels increased after transfection of AGS cells with Rictor plasmid. $\beta$-actin served as a loading control.

stomach tissue. Additionally, GC cell lines of primary tumors display low levels of Cav 1, whereas cell lines originated from metastases show high expression levels (57). In human SGC7901 cells, Cav 1 promotes anchoring-independent growth and apoptosis resistance by activating Src-dependent EGFR-ITGB1 signaling, which may indicate Cav 1 to be a potential therapeutic target for gastric metastasis (21). Mechanically sensitive caveolin-1 activation induces the PI3K/Akt/mTOR signaling pathway to promote motility and invasive in vivo formation, and metastasis of breast cancer (22). 
A

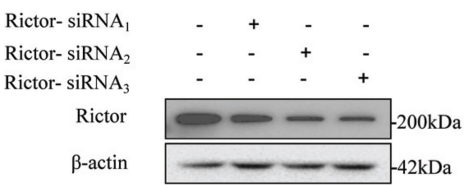

SGC-7901

C

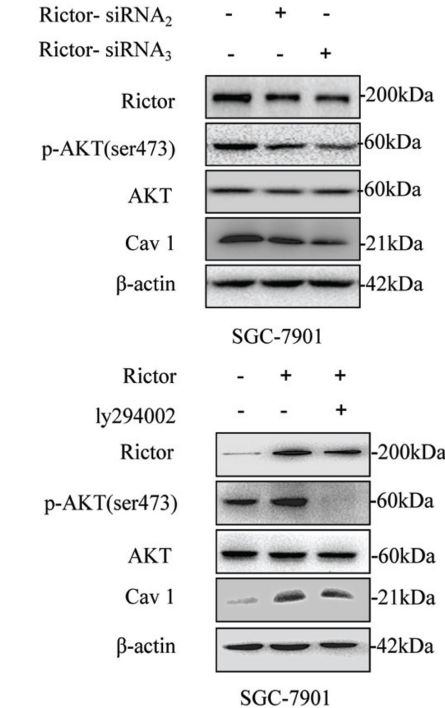

B

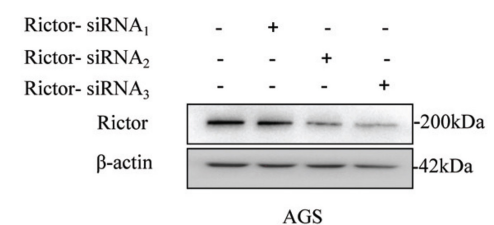

AGS

D Rictor- siRNA ${ }_{2}-+\quad+$

Rictor- siRNA3 - - +

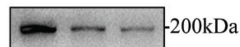

p-AKT(ser473)

AKT

Cav 1

$\beta$-actin
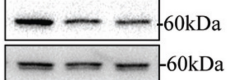

क्या

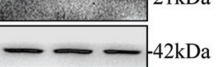

AGS

F

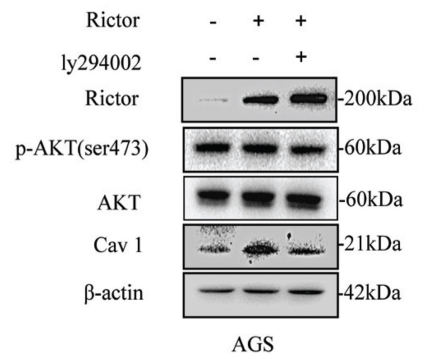

G
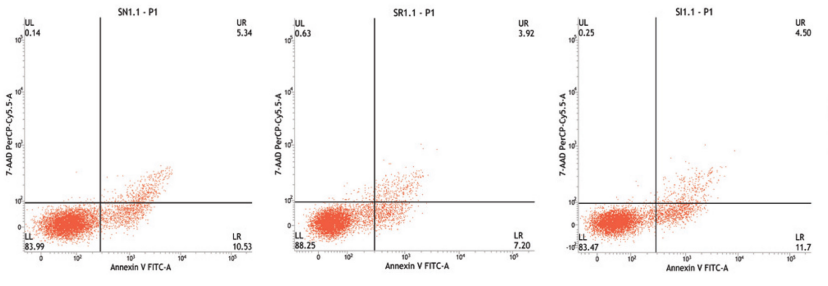

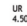

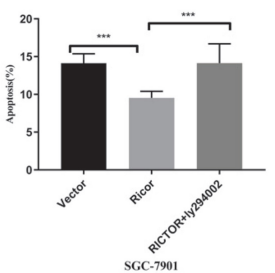

H
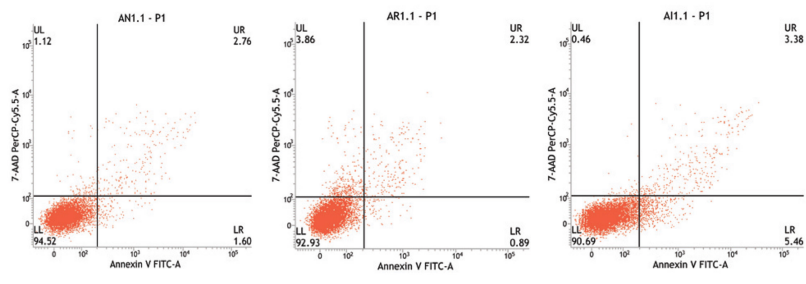

$\underset{3.38}{\text { UR }}$

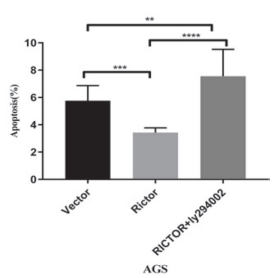

FIGURE 5 | Association between Rictor and Cav 1 analyzed using western blot and apoptosis detection. (A, B) Two different cell lines were transfected with RictorsiRNA respectively to verify Rictor-siRNA knock down efficiency. (C) Protein levels of p-Akt and Cav 1 induced by Rictor knockdown in SGC-7901 cells were assessed. (D) Protein levels of p-Akt and Cav 1 induced by Rictor knockdown in AGS cells. (E) After transfection of Rictor plasmid in SGC-7901 cells for 24 h and addition of $20 \mu \mathrm{M}$ ly294002 for $6 \mathrm{~h}$, the changes of $\mathrm{p}$-Akt and Cav 1 protein levels were detected by western blot. (F) After transfection of Rictor plasmid into AGS cells for $24 \mathrm{~h}$, and addition of $20 \mu \mathrm{M}$ ly294002 for $6 \mathrm{~h}$, the changes of p-Akt and Cav 1 protein levels were detected by western blot. $\beta$-actin served as loading control. (G) Apoptosis of SGC-7901 cells after $24 \mathrm{~h}$ transfection with Rictor plasmid and $24 \mathrm{~h}$ treatment with $20 \mu \mathrm{M}$ ly294002 ( $\mathrm{n}=3$ ). (H) Apoptosis of AGS cells after $24 \mathrm{~h}$ transfection with Rictor plasmid and $24 \mathrm{~h}$ treatment with $20 \mu \mathrm{M}$ ly294002 $(\mathrm{n}=3)$. Values represent the Means \pm SD. ${ }^{* \star} \mathrm{P}<0.01$, ${ }^{\star \star *} \mathrm{P}<0.001$ and ${ }^{\star \star \star *} \mathrm{P}<0.0001$ were calculated using Student's t-test.

We found that overexpression of Rictor led to increased expression of Cav 1. Similarly, knocking down Rictor led to decreased expression of Cav 1. By immunofluorescence, Rictor was located in the cytoplasm and Cav 1 was located on the cell membrane. There was no co-location between Rictor and Cav 1.
We speculate that there is no direct interaction between them, and that Rictor regulates Cav 1 through the Akt signaling pathway by activating Akt Ser473. This regulatory effect was reduced when Akt was inhibited by the PI3K/Akt inhibitor ly294002, and apoptosis of GC cells also increased 
A

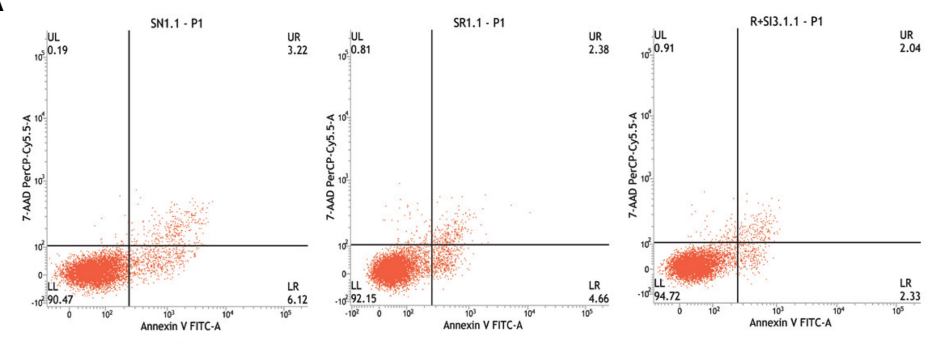

${ }_{2.04}^{\text {UR }}$

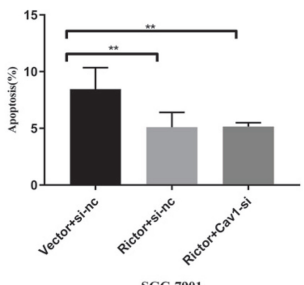

B

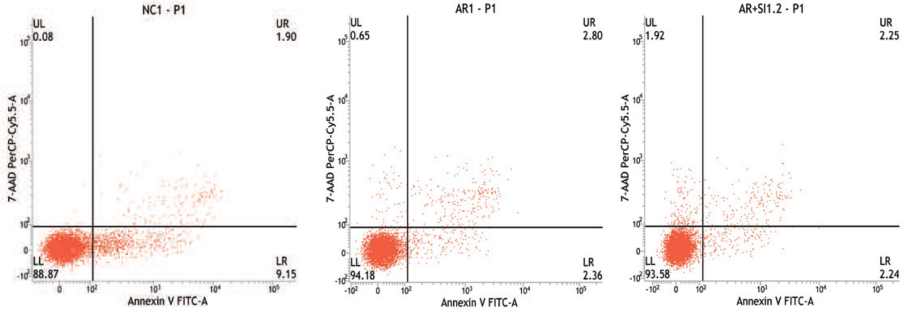

$\underset{2.25}{\substack{u R \\ 2.25}}$

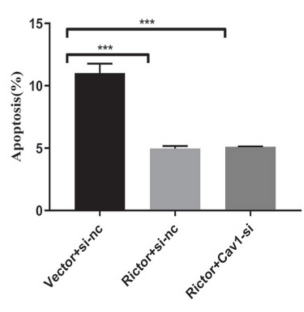

AGS

C

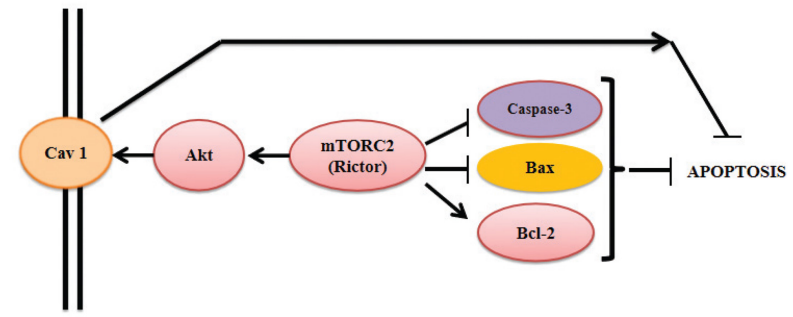

FIGURE 6 | Cav 1 knockdown has no effect on apoptosis inhibition induced by Rictor overexpression. (A) Co-transfection of Rictor plasmid and Cav 1-siRNA in SGC-7901 cells indicated that knocking down Cav 1 did not affect the inhibition of Rictor on apoptosis $(n=3)$. (B) Co-transfection with Rictor plasmid and Cav 1-siRNA in AGS cells indicated that knocking down Cav 1 did not affect the inhibition of Rictor on apoptosis $(n=3)$. Values represent the Means \pm SD. ${ }^{*} P<0.05,{ }^{* *} P<0.01$ and ${ }^{* \star *} P<0.001$ were calculated using Student's t-test. (C) Signaling pathway of Rictor and Cav 1.

significantly. However, siRNA knockdown of Cav 1 did not affect the apoptotic resistance of Rictor to GC cells. We speculate that Rictor is upstream of Cav 1 and has a positive regulatory effect on Cav 1; however, Cav 1 does not have a significant effect on Rictor. These results indicate that inhibition of Rictor/mTORC2 may prevent undesired oncogenic effects of Cav 1 simultaneously.

Targeting Rictor/mTORC2 as an anticancer therapy is an attractive prospect, since $68 \%$ of GC patients show elevated Akt levels, and mTORC2 is a critical kinase to phosphorylate Ser473 residue for full activation of Akt. Rictor/mTORC2 might be more deleterious to cancer cells than to normal cells, leading to less toxicity by selective mTORC2 inhibition. Our results also support the hypothesis that Rictor plays a critical role in GC proliferation. Our findings provide the rationale for further investigations toward mTOR kinase inhibitor targeting both mTOR complexes or specifically targeting mTORC2 as an effective therapeutic candidate against GC in the future (58).

In summary, the current study provides substantial new evidence that Rictor is involved in GC cell proliferation and increases the tumor-promoting effect of Cav 1, indicating that Rictor may serve as a feasible therapeutic target for GC.

\section{DATA AVAILABILITY STATEMENT}

The original contributions presented in the study are included in the article/supplementary material. Further inquiries can be directed to the corresponding authors.

\section{ETHICS STATEMENT}

The studies involving human participants were reviewed and approved by Ethic Committee of Capital Medical University. The patients/participants provided their written informed consent to participate in this study.

\section{AUTHOR CONTRIBUTIONS}

All authors contributed to the article and approved the submitted version. R-zC, LM, SL, and R-yT performed experiments and carried out the data analysis. H-yJ, JL, L-IS, and RC helped perform experiments and collect the primary data. S-tZ and L-IS helped analyze data. S-lG and PL conceived and designed the study. R-zC, LM, S-lG, and PL drafted the manuscript. 


\section{REFERENCES}

1. Bray F, Ferlay J, Soerjomataram I, Siegel RL, Torre LA, Jemal A. Global Cancer Statistics 2018: GLOBOCAN Estimates of Incidence and Mortality Worldwide for 36 Cancers in 185 Countries. CA Cancer J Clin (2018) 68:394424. doi: $10.3322 /$ caac. 21492

2. Wei F, Wu Y, Tang L, Xiong F, Guo C, Li X, et al. Trend Analysis of Cancer Incidence and Mortality in China. Sci China Life Sci (2017) 60:1271-5. doi: 10.1007/s11427-017-9172-6

3. Machlowska J, Baj J, Sitarz M, Maciejewski R, Sitarz R. Gastric Cancer: Epidemiology, Risk Factors, Classification, Genomic Characteristics and Treatment Strategies. Int J Mol Sci (2020) 21. doi: 10.3390/ijms21114012

4. Schinzari G, Cassano A, Orlandi A, Basso M, Barone C. Targeted Therapy in Advanced Gastric Carcinoma: The Future is Beginning. Curr Med Chem (2014) 21:1026-38. doi: 10.2174/0929867321666131129124054

5. Fanelli GN, Gasparini P, Coati I, Cui R, Pakula H, Chowdhury B, et al. LONG-NONCODING RNAs in Gastroesophageal Cancers. Noncoding RNA Res (2018) 3:195-212. doi: 10.1016/j.ncrna.2018.10.001

6. Ghafouri-Fard S, Dashti S, Taheri M, Omrani MD. TINCR: An lncRNA With Dual Functions in the Carcinogenesis Process. Noncoding RNA Res (2020) 5:109-15. doi: 10.1016/j.ncrna.2020.06.003

7. Kwok GT, Zhao JT, Weiss J, Mugridge N, Brahmbhatt H, MacDiarmid JA, et al. Translational Applications of MicroRNAs in Cancer, and Therapeutic Implications. Noncoding RNA Res (2017) 2:143-50. doi: 10.1016/ j.ncrna.2017.12.002

8. Ahadi A. The Significance of Microrna Deregulation in Colorectal Cancer Development and The Clinical Uses as A Diagnostic And Prognostic Biomarker and Therapeutic Agent. Noncoding RNA Res (2020) 5:125-34. doi: 10.1016/j.ncrna.2020.08.003

9. Pisani G, Baron B. Nuclear Paraspeckles Function in Mediating Gene Regulatory and Apoptotic Pathways. Noncoding RNA Res (2019) 4:128-34. doi: 10.1016/j.ncrna.2019.11.002

10. Bian Y, Wang Z, Xu J, Zhao W, Cao H, Zhang Z. Elevated Rictor Expression is Associated with Tumor Progression and Poor Prognosis in Patients With Gastric Cancer. Biochem Biophys Res Commun (2015) 464:534-40. doi: 10.1016/j.bbrc.2015.07.001

11. Manning BD, Toker A. AKT/PKB Signaling: Navigating the Network. Cell (2017) 169:381-405. doi: 10.1016/j.cell.2017.04.001

12. Hay N. The Akt-mTOR Tango and Its Relevance to Cancer. Cancer Cell (2005) 8:179-83. doi: 10.1016/j.ccr.2005.08.008

13. Lang SA, Hackl C, Moser C, Fichtner-Feigl S, Koehl GE, Schlitt HJ, et al. Implication of RICTOR in the mTOR Inhibitor-Mediated Induction of Insulin-Like Growth Factor-I Receptor (Igf-Ir) and Human Epidermal Growth Factor Receptor-2 (Her2) Expression in Gastrointestinal Cancer Cells. Biochim Biophys Acta (2010) 1803:435-42. doi: 10.1016/ j.bbamcr.2010.01.009

14. Chiarini F, Evangelisti C, McCubrey JA, Martelli AM. Current Treatment Strategies for Inhibiting Mtor in Cancer. Trends Pharmacol Sci (2015) 36:12435. doi: 10.1016/j.tips.2014.11.004

15. Wu SH, Bi JF, Cloughesy T, Cavenee WK, Mischel PS. Emerging Function of mTORC2 As a Core Regulator in Glioblastoma: Metabolic Reprogramming and Drug Resistance. Cancer Biol Med (2014) 11:255-63. doi: 10.7497/ j.issn.2095-3941

16. Masui K, Harachi M, Cavenee WK, Mischel PS, Shibata N. mTOR Complex 2 is An Integrator of Cancer Metabolism and Epigenetics. Cancer Lett (2020) 478:1-7. doi: 10.1016/j.canlet.2020.03.001

17. Wang Y, Song Y, Che X, Zhang L, Wang Q, Zhang X, et al. Caveolin1 Enhances RANKLinduced Gastric Cancer Cell Migration. Oncol Rep (2018) 40:1287-96. doi: 10.3892/or.2018.6550

18. Kannan A, Krishnan A, Ali M, Subramaniam S, Halagowder D, Sivasithamparam ND. Caveolin-1 Promotes Gastric Cancer Progression by Up-Regulating Epithelial to Mesenchymal Transition by Crosstalk of Signalling Mechanisms Under Hypoxic Condition. Eur J Cancer (2014) 50:204-15. doi: 10.1016/j.ejca.2013.08.016

19. Zhang K, Yang G, Wu W, Zhang J, Xia X, Jiang T, et al. Decreased Expression of Caveolin-1 and E-Cadherin Correlates with the Clinicopathologic Features of Gastric Cancer and the EMT Process. Recent Pat Anticancer Drug Discov (2016) 11:236-44. doi: 10.2174/1574892811666160128151437
20. Hamoudane M, Maffioli S, Cordera R, Maggi D, Salani B. Caveolin-1 and Polymerase I and Transcript Release Factor: New Players in Insulin-Like Growth Factor-I Receptor Signaling. J Endocrinol Invest (2013) 36:204-8. doi: $10.3275 / 8848$

21. Wang K, Zhu X, Mei D, Ding Z. Caveolin-1 Contributes to Anoikis Resistance in Human Gastric Cancer SGC-7901 Cells Via Regulating Src-Dependent EGFR-ITGB1 Signaling. J Biochem Mol Toxicol (2018) 32:e22202. doi: $10.1002 / \mathrm{jbt} .22202$

22. Yang H, Guan L, Li S, Jiang Y, Xiong N, Li L, et al. Mechanosensitive Caveolin-1 Activation-Induced PI3K/Akt/mTOR Signaling Pathway Promotes Breast Cancer Motility, Invadopodia Formation and Metastasis In Vivo. Oncotarget (2016) 7:16227-47. doi: 10.18632/oncotarget.7583

23. Ahmad A, Biersack B, Li Y, Kong D, Bao B, Schobert R, et al. Deregulation of PI3K/Akt/mTOR Signaling Pathways by Isoflavones and Its Implication in Cancer Treatment. Anticancer Agents Med Chem (2013) 13:1014-24. doi: 10.2174/18715206113139990117

24. Sasaki T, Yamashita Y, Kuniyasu H. AKT Plays A Crucial Role in Gastric Cancer. Oncol Lett (2015) 10:607-11. doi: 10.3892/ol.2015.3260

25. Ahmad A, Biersack B, Li Y, Kong D, Bao B, Schobert R, et al. Targeted Regulation of PI3K/Akt/mTOR/NF-kappaB Signaling by Indole Compounds and Their Derivatives: Mechanistic Details and Biological Implications for Cancer Therapy. Anticancer Agents Med Chem (2013) 13:1002-13. doi: $10.2174 / 18715206113139990078$

26. Sasaki T, Kuniyasu H. Significance of AKT in Gastric Cancer (Review). Int $J$ Oncol (2014) 45:2187-92. doi: 10.3892/ijo.2014.2678

27. Lu Z, Luo T, Pang T, Du Z, Yin X, Cui H, et al. MALAT1 Promotes Gastric Adenocarcinoma Through The MALAT1/miR-181a-5p/AKT3 axis. Open Biol (2019) 9:190095. doi: 10.1098/rsob.190095

28. Zhuo W, Liu Y, Li S, Guo D, Sun Q, Jin J, et al. Long Noncoding RNA GMAN, Up-Regulated in Gastric Cancer Tissues, Is Associated With Metastasis in Patients and Promotes Translation of Ephrin Al by Competitively Binding GMAN-AS. Gastroenterology (2019) 156:676-91.e11. doi: 10.1053/ j.gastro.2018.10.054

29. Sun M, Xia R, Jin F, Xu T, Liu Z, De W, et al. Downregulated Long Noncoding RNA MEG3 is Associated With Poor Prognosis and Promotes Cell Proliferation in Gastric Cancer. Tumour Biol (2014) 35:1065-73. doi: 10.1007/s13277-013-1142-z

30. Mossmann D, Park S, Hall MN. mTOR Signalling and Cellular Metabolism are Mutual Determinants in Cancer. Nat Rev Cancer (2018) 18:744-57. doi: 10.1038/s41568-018-0074-8

31. Murugan AK. mTOR: Role in Cancer, Metastasis and Drug Resistance. Semin Cancer Biol (2019) 59:92-111. doi: 10.1016/j.semcancer.2019.07.003

32. Xu DZ, Geng QR, Tian Y, Cai MY, Fang XJ, Zhan YQ, et al. Activated Mammalian Target of Rapamycin is A Potential Therapeutic Target in Gastric Cancer. BMC Cancer (2010) 10:536. doi: 10.1186/1471-2407-10-536

33. Sun B, Chen L, Fu H, Guo L, Guo H, Zhang N. Upregulation of RICTOR Gene Transcription by The Proinflammatory Cytokines Through NF-kappaB Pathway Contributes to The Metastasis of Renal Cell Carcinoma. Tumour Biol (2016) 37:4457-66. doi: 10.1007/s13277-015-4296-z

34. Morrison Joly M, Hicks DJ, Jones B, Sanchez V, Estrada MV, Young C, et al. Rictor/mTORC2 Drives Progression and Therapeutic Resistance of HER2Amplified Breast Cancers. Cancer Res (2016) 76:4752-64. doi: 10.1158/00085472.CAN-15-3393

35. Brown MC, Dobrikov MI, Gromeier M. Mitogen-Activated Protein KinaseInteracting Kinase Regulates mTOR/AKT signaling and Controls The Serine/ Arginine-Rich Protein Kinase-Responsive Type 1 Internal Ribosome Entry Site-Mediated Translation and Viral Oncolysis. J Virol (2014) 88:13149-60. doi: 10.1128/JVI.01884-14

36. Gulhati P, Cai Q, Li J, Liu J, Rychahou PG, Qiu S, et al. Targeted Inhibition of Mammalian Target of Rapamycin Signaling Inhibits Tumorigenesis of Colorectal Cancer. Clin Cancer Res (2009) 15:7207-16. doi: 10.1158/10780432.CCR-09-1249

37. Zhang X, Wang X, Xu T, Zhong S, Shen Z. Targeting of mTORC2 May Have Advantages Over Selective Targeting of mTORC1 in the Treatment of Malignant Pheochromocytoma. Tumour Biol (2015) 36:5273-81. doi: 10.1007/s13277-015-3187-7

38. Laugier F, Finet-Benyair A, Andre J, Rachakonda PS, Kumar R, Bensussan A, et al. RICTOR Involvement in the PI3K/AKT Pathway Regulation In 
Melanocytes and Melanoma. Oncotarget (2015) 6:28120-31. doi: 10.18632/ oncotarget.4866

39. Micevic G, Muthusamy V, Damsky W, Theodosakis N, Liu X, Meeth K, et al. DNMT3b Modulates Melanoma Growth by Controlling Levels of mTORC2 Component RICTOR. Cell Rep (2016) 14:2180-92. doi: 10.1016/j.celrep.2016.02.010

40. Chatterjee P, Seal S, Mukherjee S, Kundu R, Bhuyan M, Barua NC, et al. A Carbazole Alkaloid Deactivates mTOR Through The Suppression of Rictor and That Induces Apoptosis In Lung Cancer Cells. Mol Cell Biochem (2015) 405:149-58. doi: 10.1007/s11010-015-2406-2

41. Nwosu ZC, Ebert MP, Dooley S, Meyer C. Caveolin-1 In The Regulation of Cell Metabolism: A Cancer Perspective. Mol Cancer (2016) 15:71. doi: 10.1186/s12943-016-0558-7

42. Sotgia F, Martinez-Outschoorn UE, Howell A, Pestell RG, Pavlides S, Lisanti MP. Caveolin-1 and Cancer Metabolism in The Tumor Microenvironment: Markers, Models, and Mechanisms. Annu Rev Pathol (2012) 7:423-67. doi: 10.1146/annurev-pathol-011811-120856

43. Chidlow JH Jr, Sessa WC. Caveolae, Caveolins, and Cavins: Complex Control of Cellular Signalling and Inflammation. Cardiovasc Res (2010) 86:219-25. doi: $10.1093 / \mathrm{cvr} / \mathrm{cvq} 075$

44. Xu H, Zhang L, Chen W, Xu J, Zhang R, Liu R, et al. Inhibitory Effect of Caveolin-1 In Vascular Endothelial Cells, Pericytes and Smooth Muscle Cells. Oncotarget (2017) 8:76165-73. doi: 10.18632/oncotarget.19191

45. Zimnicka AM, Husain YS, Shajahan AN, Sverdlov M, Chaga O, Chen Z, et al. Src-Dependent Phosphorylation of Caveolin-1 Tyr-14 Promotes Swelling and Release of Caveolae. Mol Biol Cell (2016) 27:2090-106. doi: 10.1091/mbc.E1511-0756

46. Gottlieb-Abraham E, Shvartsman DE, Donaldson JC, Ehrlich M, Gutman O, Martin GS, et al. Src-Mediated Caveolin-1 Phosphorylation Affects The Targeting of Active Src to Specific Membrane Sites. Mol Biol Cell (2013) 24:3881-95. doi: 10.1091/mbc.e13-03-0163

47. Tahir SA, Park S, Thompson TC. Caveolin-1 Regulates VEGF-Stimulated Angiogenic Activities In Prostate Cancer and Endothelial Cells. Cancer Biol Ther (2009) 8:2286-96. doi: 10.4161/cbt.8.23.10138

48. Torres VA, Tapia JC, Rodriguez DA, Parraga M, Lisboa P, Montoya M, et al. Caveolin-1 Controls Cell Proliferation and Cell Death by Suppressing Expression of The Inhibitor of Apoptosis Protein Survivin. J Cell Sci (2006) 119:1812-23. doi: 10.1242/jcs.02894

49. Xu L, Qu X, Li H, Li C, Liu J, Zheng H, et al. Src/Caveolin-1-Regulated EGFR Activation Antagonizes TRAIL-Induced Apoptosis in Gastric Cancer Cells. Oncol Rep (2014) 32:318-24. doi: 10.3892/or.2014.3183

50. Meyer C, Liu Y, Kaul A, Peipe I, Dooley S. Caveolin-1 Abrogates TGF-Beta Mediated Hepatocyte Apoptosis. Cell Death Dis (2013) 4:e466. doi: 10.1038/ cddis.2012.204
51. Zou W, Ma X, Hua W, Chen B, Cai G. Caveolin-1 Mediates Chemoresistance in Cisplatin-Resistant Ovarian Cancer Cells by Targeting Apoptosis Through The Notch-1/Akt/NF-kappaB Pathway. Oncol Rep (2015) 34:3256-63. doi: 10.3892/or.2015.4320

52. Fine SW, Lisanti MP, Galbiati F, Li M. Elevated Expression of Caveolin-1 In Adenocarcinoma of The Colon. Am J Clin Pathol (2001) 115:719-24. doi: 10.1309/YL54-CCU7-4V0P-FDUT

53. Li T, Sotgia F, Vuolo MA, Li M, Yang WC, Pestell RG, et al. Caveolin-1 Mutations In Human Breast Cancer: Functional Association With Estrogen Receptor Alpha-Positive Status. Am J Pathol (2006) 168:1998-2013. doi: 10.2353/ajpath.2006.051089

54. Ryu BK, Lee MG, Kim NH, Lee KY, Oh SJ, Moon JR, et al. Bidirectional Alteration Of Cav-1 Expression is Associated With Mitogenic Conversion of Its Function in Gastric Tumor Progression. BMC Cancer (2017) 17:766. doi: 10.1186/s12885-017-3770-y

55. Seker M, Aydin D, Bilici A, Yavuzer D, Ozgun MG, Ozcelik M, et al. Correlation of Caveolin-1 Expression with Prognosis in Patients with Gastric Cancer after Gastrectomy. Oncol Res Treat (2017) 40:185-90. doi: $10.1159 / 000456620$

56. Nam KH, Lee BL, Park JH, Kim J, Han N, Lee HE, et al. Caveolin 1 Expression Correlates With Poor Prognosis and Focal Adhesion Kinase Expression in Gastric Cancer. Pathobiology (2013) 80:87-94. doi: 10.1159/000341685

57. Burgermeister E, Xing X, Rocken C, Juhasz M, Chen J, Hiber M, et al. Differential Expression and Function of Caveolin-1 In Human Gastric Cancer Progression. Cancer Res (2007) 67:8519-26. doi: 10.1158/0008-5472.CAN-071125

58. Kim ST, Kim SY, Klempner SJ, Yoon J, Kim N, Ahn S, et al. RapamycinInsensitive Companion of mTOR (RICTOR) Amplification Defines A Subset of Advanced Gastric Cancer and Is Sensitive to AZD2014-mediated mTORC1/2 inhibition. Ann Oncol (2017) 28:547-54. doi: 10.1093/annonc/ mdw669

Conflict of Interest: The authors declare that the research was conducted in the absence of any commercial or financial relationships that could be construed as a potential conflict of interest.

Copyright (C) 2021 Cao, Min, Liu, Tian, Jiang, Liu, Shao, Cheng, Zhu, Guo and Li. This is an open-access article distributed under the terms of the Creative Commons Attribution License (CC BY). The use, distribution or reproduction in other forums is permitted, provided the original author(s) and the copyright owner(s) are credited and that the original publication in this journal is cited, in accordance with accepted academic practice. No use, distribution or reproduction is permitted which does not comply with these terms. 